\title{
Cloning, phylogenetic research, and prokaryotic expression study of the metabolic detoxification gene EoGSTs1 in Empoasca onukii Matsuda
}

\author{
Yujie Zhang ${ }^{1,2}$, Wenlong Chen ${ }^{1,2}$, Ming Li $^{3}$, Lin Yang ${ }^{1,2}$, Xiangsheng Chen ${ }^{\text {Corresp. } 1,2}$ \\ 1 Institute of Entomology, Guizhou University, Guiyang, China \\ 2 Guizhou Key Laboratory for Plant Pest Management of Mountainous Region, Guizhou University, Guiyang, China \\ ${ }^{3}$ The Provincial Special Key Laboratory for Development and Utilization of Insect Resources of Guizhou, Guiyang, China \\ Corresponding Author: Xiangsheng Chen \\ Email address: chenxs3218@163.com
}

Due to the misuse of chemical pesticides, small green leafhoppers (Empoasca onukii Matsuda) have developed resistance to pesticides, thereby posing a serious problem to the tea industry. Glutathione S-transferases (GSTs) are an important family of enzymes that are involved in pesticide resistance in Empoasca onukii Matsuda. Empoasca onukii GST sigma 1 (EoGSTs1, GenBank Accession number MK443501) is a member of the GST family. In this study, the full-length CDNA of EoGSTs1 was cloned by reverse transcription polymerase chain reaction (qPCR), and its taxonomic identity was examined. Furthermore, we performed bioinformatics and phylogenetic analyses of the gene and structural and functional domain prediction of the protein. The results demonstrate that EoGSTS1 belongs to the Sigma family of GSTs; the full-length EoGSTs1 cDNA is 841 bp with a 624-bp coding region that encodes a 23.68932-kDa protein containing 207 amino acids. The theoretical isoelectric point (IEP) was calculated to be 6.00. Phylogenetic analysis indicates that EoGSTS1 is closely related to the Sub psaltriayangi subfamily of the Cicadoidea superfamily in order Hemiptera, whereas it is distantly related to Periplaneta americana of order Blattodea. Amino acid sequence alignment of EoGSTS1 and GSTs from four other insects of order Hemiptera revealed protein sequence conservation. Tertiary structure analysis and structural domain functional predictions of the protein revealed that EoGSTS1 contains nine $\alpha$ helices and two $\beta$ sheets with one conserved GST domain. The results of enzyme activity assay showed that recombinant EoGSTs1 (rEoGSTs1) protein had catalytic activity for substrate 1-chloro-2,4-dinitrobenzene (CDNB) and exhibited the highest activity at $\mathrm{pH} 7$ and $25^{\circ} \mathrm{C}$. The Michaelis constant $\mathrm{Km}$ of rEoGSTs1 protein was $0.07782 \pm 0.01990$ $\mathrm{mmol} / \mathrm{L}$, and the maximum reaction rate $V \max$ was $12.15 \pm 1.673 \mu \mathrm{mol} / \mathrm{min} \cdot \mathrm{mg}$. Our study clarified the taxonomic identity of small green leafhopper EoGSTs1 and revealed some properties of the gene and its encoded protein sequence. According to the catalytic 
activity of the rEoGSTs1 enzyme on the model substrate CDNB, we infer that it functions in the degradation of exogenous substances. 


\section{Cloning, phylogenetic research, and prokaryotic}

\section{2 expression study of the metabolic detoxification gene}

\section{EoGSTs1 in Empoasca onukii Matsuda}

4

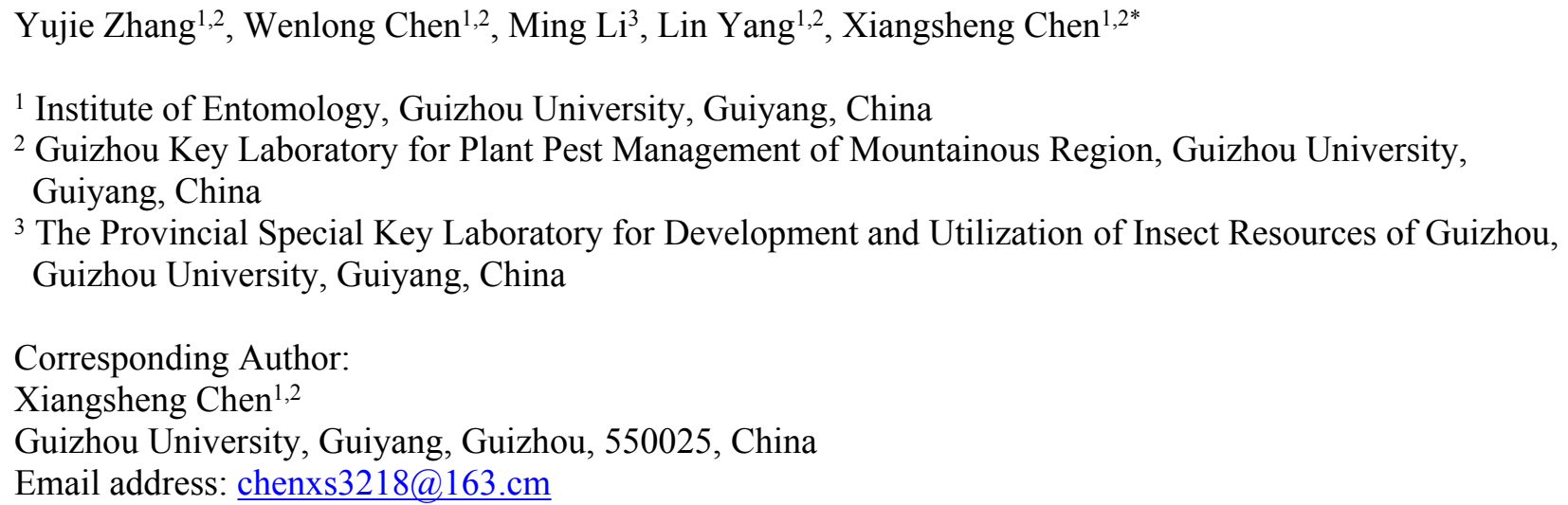

\section{ABSTRACT}

Due to the misuse of chemical pesticides, small green leafhoppers (Empoasca onukii Matsuda) have developed resistance to pesticides, thereby posing a serious problem to the tea industry. Glutathione S-transferases (GSTs) are an important family of enzymes that are involved in pesticide resistance in Empoasca onukii Matsuda. Empoasca onukii GST sigma 1 (EoGSTs 1, GenBank Accession number MK443501) is a member of the GST family. In this study, the fulllength cDNA of EoGSTs 1 was cloned by reverse transcription polymerase chain reaction (qPCR), and its taxonomic identity was examined. Furthermore, we performed bioinformatics and phylogenetic analyses of the gene and structural and functional domain prediction of the protein. The results demonstrate that EoGSTS1 belongs to the Sigma family of GSTs; the fulllength EoGSTs 1 cDNA is 841 bp with a $624-\mathrm{bp}$ coding region that encodes a $23.68932-\mathrm{kDa}$ 
29 protein containing 207 amino acids. The theoretical isoelectric point (IEP) was calculated to be

30 6.00. Phylogenetic analysis indicates that EoGSTS1 is closely related to the Sub psaltriayangi

31 subfamily of the Cicadoidea superfamily in order Hemiptera, whereas it is distantly related to

32 Periplaneta americana of order Blattodea. Amino acid sequence alignment of EoGSTS1 and

33 GSTs from four other insects of order Hemiptera revealed protein sequence conservation.

34 Tertiary structure analysis and structural domain functional predictions of the protein revealed 35 that EoGSTS1 contains nine $\alpha$ helices and two $\beta$ sheets with one conserved GST domain. The 36 results of enzyme activity assay showed that recombinant EoGSTs1 (rEoGSTs1) protein had 37 catalytic activity for substrate 1-chloro-2,4-dinitrobenzene (CDNB) and exhibited the highest 38 activity at $\mathrm{pH} 7$ and $25^{\circ} \mathrm{C}$. The Michaelis constant $\mathrm{Km}$ of rEoGSTs 1 protein was $0.07782 \pm$ $390.01990 \mathrm{mmol} / \mathrm{L}$, and the maximum reaction rate Vmax was $12.15 \pm 1.673 \mu \mathrm{mol} / \mathrm{min} \cdot \mathrm{mg}$. Our 40 study clarified the taxonomic identity of small green leafhopper EoGSTs 1 and revealed some 41 properties of the gene and its encoded protein sequence. According to the catalytic activity of the 42 rEoGSTs 1 enzyme on the model substrate CDNB, we infer that it functions in the degradation of 43 exogenous substances.

\section{INTRODUCTION}

Small green leafhoppers or tea green leafhoppers, Empoasca onukii Matsuda, belong to the

Cicadidae family in genus Jacobiasca formosana. Small green leafhoppers are one of the most predominant insects that infiltrate tea production fields. Small green leafhoppers are extremely harmful to tea trees, causing a $15 \%-50 \%$ loss of production of tea each year in mainland China and Taiwan (Niu, et al., 2015; Hazarika, Bhuyan \& Hazarika, 2009; Fu, Han \& Xiao, 2014; 
52 2012). To date, the pest control and prevention of small green leafhoppers still mainly rely on 53 chemicals. Due to long-term misuse and abuse of chemical compounds, insects have developed 54 resistance to most chemical pesticides (Zhan et al., 2012). For instance, Wang et al. (2004) 55 performed drug membrane interaction tests on the resistance of small green leafhoppers to 14 56 chemical pesticides and found that their LC50 values and resistance gradually increased with the 57 higher pesticide doses used in tea tree facilities. In particular, the resistance to thiamethoxam 58 increased by 2.2- to 13.3-fold, which is the largest increase among all the chemical pesticides.

59 Glutathione S-transferases (GSTs) are a family of enzymes that widely exist in aerobic 60 organisms and play an important role in detoxifying insects from endogenous or exogenous 61 toxins (Enayati, Ranson \& Hemingway, 2005). For example, Wu et al. (2016) used cycloxaprid 62 as a toxin to induce the activities of detoxification enzymes in Alfalfa aphid and found that the 63 activities of GSTs in this species that survived treatment were significantly higher than those in 64 control insects. Thus, they suggested that GSTs play a critical role in detoxifying cycloxaprid in 65 Alfalfa aphid. Zhang et al. (2014) studied the levels of pest resistance to the neonicotinoid class 66 of insecticides and the synergistic effect of enzyme inhibitors in Aphis gossypii in different 67 regions of Shandong Province, China. They discovered a noticeable synergistic effect on this 68 class of insecticides by the enzyme inhibitor diethyl maleate (DEM). Cytoplasmic GSTs in 69 insects are divided into six subfamilies, which include Epsilon, Delta, Zeta, Omega, Sigma, and 70 Theta (Chelvanayagam, Parker \& Board, 2001). To date, studies on resistance to pesticides 71 related to GSTs in insects have focused on the Epsilon and Delta subfamilies, whereas 72 investigations on the involvement of other subfamilies of GSTs are limited (Yu et al., 2010). In 73 recent years, with the rapid development of techniques in molecular biotechnology, studies on 
74 other GST subfamilies related to pesticide resistance have grown in number, although studies on 75 GST-related pesticide resistance in E. onukii Matsuda remain scarce.

76 Pesticide resistance in E. onukii can further increase in the foreseeable future because of 77 current continuous misuse of chemical pesticides. Reducing or slowing down this process of 78 increasing pesticide resistance has thus become a major goal. Research on genes involved in the 79 resistance of small green leafhoppers can provide critical and fundamental knowledge for the 80 development of new pesticides, recipes for pesticide cocktails, or protocols for alternating the 81 usage of different chemicals (Zhou \& Han, 2017). GSTs are the major enzymes involved in 82 metabolic resistance and have been proven essential in the detoxification of small green 83 leafhoppers that are resistant to chlorpyrifos and thiamethoxam. In this study, we screened 84 transcriptome data and identified genes that are differentially expressed in E. onukii upon 85 chemical treatment and discovered that the expression level of the GST cluster-166.0 was 86 significantly upregulated. Therefore, we cloned GST cluster-166.0 using reverse transcription 87 polymerase chain reaction (qPCR) with proofreading. Bioinformatics analysis, phylogenetic reconstruction, and homology modeling of the full-length cDNA and its encoded protein 89 sequence were conducted to obtain biological information on the E. onukii GST gene (EoGSTs1, 90 cluster-166.0), including its physical and chemical properties, taxonomic classification, and the 91 spatial structure of the EoGSTS1 protein. In addition, the expression vector of the EoGSTS1 92 protein was constructed for the expression in prokaryotic cells, and the expression of fusion 93 protein was detected by western blotting. Finally, the enzyme activity of purified EoGSTS1 94 protein was determined, and its enzymatic characteristics were verified. This information may 95 serve as the foundation for future applications of EoGSTs 1, may be used as a theoretical 
96 reference for the detection and comprehensive management of chemical resistance in small green

97 leafhoppers, as well as employed in the development and utilization of new pesticides.

98

99 MATERIALS AND METHODS

\section{Preparation of insect samples}

101 E. onukii Matsuda used in this study is a sensitive strain that has been cultured in the laboratory

102 for many generations. Insects were maintained in a light incubator with a constant temperature of $10325^{\circ} \mathrm{C} \pm 1{ }^{\circ} \mathrm{C}$, a humidity of $70 \% \pm 5 \%$, and a photoperiod of 16:8 (L:D). Small green leafhoppers

104 of approximately the same size were starved for $1 \mathrm{~h}$ and then treated with $2.5 \mu \mathrm{g} / \mathrm{mL}$ of

105 thiamethoxam for $48 \mathrm{~h}$. Individuals who survived the treatment were collected at 20 insects/tube,

106 flash frozen in liquid nitrogen, and stored in a $-80^{\circ} \mathrm{C}$ freezer.

\section{Extraction and examination of total RNA}

108 Total RNA was extracted using the TRIzol® PlusRNA Purification Kit (Cat. No. 12183-555,

109 Invitrogen, Carlsbad, CA, USA) following the manufacturer's instructions. The extracted RNAs

110 were examined by NanoDrop quantification and electrophoresis. Three microliters of each

111 extracted RNA sample were used in agarose gel (1\%) electrophoresis.

\section{Primer design and template synthesis}

113 Primers were designed using Primer Premier 6.0 (Premier Biosoft International, Palo Alto, CA,

114 USA). Specific primer sequences are listed in Table 1. The 5' rapid amplification of cDNA ends

115 (RACE) and 3' RACE templates were synthesized using a GeneRacer ${ }^{\mathrm{TM}}$ Kit (Cat. No. 12183-555,

116 Invitrogen, Carlsbad, CA, USA). The cDNA template used for intermediate fragment PCR was

117 synthesized using the SuperScript ${ }^{\mathrm{TM}}$ III First-Strand Synthesis SuperMix (Cat. No. 18080-400,

118 Invitrogen, Carlsbad, CA, USA) for qPCR Kit. 
119 PCR: The reaction system and conditions for 5' RACE PCR, intermediate fragment PCR, and 3'

120 RACE PCR are presented in Tables S1-S10.

\section{Prokaryotic expression and purification}

122 Full-length splicing primers were designed based on PCR-based accurate synthesis (PAS).

123 Protective bases were designed at both ends of the primers to synthesize the EoGSTs1-TARGET

124 gene, which connected the site between the NdeI and XbaI sites of vector PCZN1. The obtained

125 recombinant plasmid PCZN1-EoGSTs1-TARGET was transferred into Escherichia coli strain

126 Top10, and positive clones were selected for sequencing and restriction enzyme digestion to

127 ensure the correct expression plasmid was obtained through subcloning.

128 Approximately $1 \mu \mathrm{L}$ of the constructed expression plasmid was added to $100 \mu \mathrm{L}$ of Arctic

129 Express E. coli, placed on the ice for $20 \mathrm{~min}$, heat-shocked for $90 \mathrm{~s}$ at $42^{\circ} \mathrm{C}$, placed on ice for 5

130 min, added $600 \mathrm{~mL}$ of LB culture medium, and placed on a shaker for $1 \mathrm{~h}$ at the frequency of

$131220 \mathrm{rpm}$ and $37^{\circ} \mathrm{C}$. After centrifugation, all the samples were coated onto LB plates that

132 contained $50 \mu \mathrm{g} / \mathrm{mL}$ Amp (ampicillin), and incubated overnight at $37^{\circ} \mathrm{C}$. Monoclones were

133 selected and inoculated into $3 \mathrm{~mL}$ of LB medium containing $50 \mu \mathrm{L} / \mathrm{mL}$, placed on a shaker

134 overnight at the frequency of $220 \mathrm{rpm}$ and $37^{\circ} \mathrm{C}$, inoculated into $30 \mathrm{~mL}$ of LB medium

135 (containing $50 \mu \mathrm{L} / \mathrm{mL}$ AMP) at a ratio of 1:100 the next day, and placed on a shaker at a

136 frequency of $220 \mathrm{rpm}$ and $37^{\circ} \mathrm{C}$ when the OD600 value of the culture reached $0.6-0.8$. Then, 1

$137 \mathrm{~mL}$ of the culture was collected and centrifuged for $2 \mathrm{~min}$ at 10,000 rpm at room temperature.

138 The supernatant discarded, and the pellet was resuspended in $100 \mu \mathrm{L} 1 \times$ sample loading buffer.

139 IPTG was added to the remaining culture until the final concentration was $0.5 \mathrm{mM}$ and placed on

140 a shaker overnight at a frequency of $220 \mathrm{rpm}$ and $11^{\circ} \mathrm{C}$ to induce the expression of the fusion

141 protein. Then, $1 \mathrm{~mL}$ of the culture was collected and centrifuged for $2 \mathrm{~min}$ at 10,000 rpm at room 
142 temperature, the supernatant was discarded, and the pellet was resuspended in $100 \mu \mathrm{L}$ of $1 \times$

143 sample loading buffer. The remaining culture was centrifuged for $10 \mathrm{~min}$ at $4000 \mathrm{rpm}$, the

144 supernatant was discarded, and the pellet was resuspended in phosphate-buffered saline (PBS).

145 The cells in suspension were then lysed by sonication, the supernatant and pellet were

146 resuspended in sample loading buffer, detected by $12 \%$ SDS-PAGE, and stained with Coomassie

147 brilliant blue.

148 The results of the preliminary experiment showed that the target protein was soluble.

149 Therefore, the supernatant was purified by Ni affinity chromatography. The supernatant solution

150 (flow rate: $0.5 \mathrm{~mL} / \mathrm{min}$ ) was loaded onto the Ni-IDA-Sepharose Cl-6B affinity chromatography

151 column (pre-equilibrated with Ni-IDA binding buffer) with a low-pressure chromatography

152 system and washed with Ni-IDA binding buffer at the flow rate of $0.5 \mathrm{~mL} / \mathrm{min}$ until the OD280

153 value of the effluent reached the baseline. The column was washed with Ni-IDA washing buffer

154 (20 mM Tris-HCl, $20 \mathrm{mM}$ imidazole, $0.15 \mathrm{M} \mathrm{NaCl}, \mathrm{pH} 8.0$ ) at the flow rate of $1 \mathrm{~mL} / \mathrm{min}$ until

155 the OD280 value of the effluent reached the baseline. Then, the target protein was eluted with

156 Ni-IDA elution buffer (20 mM Tris-HCl, $250 \mathrm{mM}$ imidazole, $0.15 \mathrm{M} \mathrm{NaCl}, \mathrm{pH} 8.0)$ at a flow

157 rate of $1 \mathrm{~mL} / \mathrm{min}$, and effluent was collected. The above-mentioned protein solution was poured

158 into a dialysis bag, and PBS $\left(3.58 \mathrm{~g} \mathrm{Na}_{2} \mathrm{HPO}_{4} \cdot 12 \mathrm{H}_{2} \mathrm{O}, 8.8 \mathrm{~g} \mathrm{NaCl}, 0.2 \mathrm{~g} \mathrm{KCl}, 0.27 \mathrm{~g} \mathrm{KH}_{2} \mathrm{P}_{4}\right)$

159 was used for overnight dialysis, then detected by $12 \%$ SDS-PAGE.

160 Western blot analysis

161 A 3- $\mu \mathrm{L}$ sample was loaded into a well of a polyacrylamide gel. After running the stacking gel at

$16290 \mathrm{~V}$ and then increased to $200 \mathrm{~V}$ until the end of electrophoresis, conducted PVDF

163 transmembrane (constant pressure $100 \mathrm{~V}, 1.5 \mathrm{~h}$, constant current $250 \mathrm{~mA}$ ), the membrane was

164 washed four times ( 5 min each time) with phosphate-buffered saline-Tween 20 (PBST) and then 
165 kept in the blocking buffer containing 5\% non-fat milk for $1 \mathrm{~h}$ at $37^{\circ} \mathrm{C}$. The membrane was

166 incubated overnight with a term primary antibody that was diluted in the blocking buffer

167 (dilution rate, 1:1000). The next day, the membrane was washed four times (5 min each time)

168 with PBST. The membrane was then incubated with a secondary HRP antibody that was diluted

169 with the blocking buffer with $5 \%$ milk (dilution rate, $1: 5000$ ) for $1 \mathrm{~h}$ at $37^{\circ} \mathrm{C}$. Then, the

170 membrane was washed four times ( 5 min each time) in a clean box, developed, and exposed by

171 the ECL (electrochemiluminescence) method.

172 Enzyme activity determination

173 Parameters of enzymatic kinetic: The determination method was based on Li et al. (2018) with

174 minor modifications. The reaction system consisted of phosphate buffer $(100 \mathrm{mmol} / \mathrm{L})$,

175 rEoGSTs1 protein $(0.12 \mathrm{mg})$, and $\operatorname{GSH}(0.01,0.02,0.04,0.06,0.08$, and $0.1 \mathrm{mmol} / \mathrm{L})$. After

176 mixing the above solution, the mixture was incubated with 1-chloro-2,4-dinitrobenzene (CDNB)

177 solution $(10 \mathrm{mmol} / \mathrm{L})$ at $35^{\circ} \mathrm{C}$ for $15 \mathrm{~min}$, then $20 \mu \mathrm{L}$ of the $\mathrm{CDNB}$ solution was added into the

178 mixture, and the volume was set to $200 \mu \mathrm{L}$. Subsequently, the absorbance was measured at a

179 wavelength of $340 \mathrm{~nm}$ in theMultiskan GO 1510 spectrophotometer (Thermo Fisher Scientific,

180 Vantaa, Finland), $30 \mathrm{~s}$ for each time and for a total of $2 \mathrm{~min}$. Enzyme activity was calculated

181 using the recombinant-inactivating protein as control. The specific activity was calculated

182 according to the following formula, and the obtained data were submitted to GraphPad Prism

183 8.0.1 to calculate for enzyme kinetics using the following equation:

184

Specific activity $(\mu \mathrm{mol} / \mathrm{min} \bullet \mathrm{mg})=\frac{\Delta \mathrm{OD}_{340} \times \mathrm{V}}{\varepsilon \times \mathrm{T} \times \mathrm{L} \times \mathrm{E}}$.

185 Note: OD340: Change in absorbance per unit time; V: enzymatic reaction volume (200 mL); $\varepsilon$ : extinction

186 coefficient of product $(9.6 \mathrm{mmol} / \mathrm{cm})$; T: reaction time $(2 \mathrm{~min})$; L: optical path $(1 \mathrm{~cm})$; and E: amount of

187 enzyme added $(0.12 \mathrm{mg})$.

Peer) reviewing PDF | (2019:03:35500:2:0:NEW 19 Jul 2019) 
To determine the effect of temperature on the activity of the purified rEoGSTs 1protein,

189 Glutathione S-transferase (GSH-ST) assay kit (Colorimetric method) was used (Cat. No. A004,

190 Nanjing Jiancheng Bioengineering Institute, Nanjing, Jiangsu, China), following the

191 manufacturer's protocol. Approximately $0.12 \mathrm{mg}$ of the rEoGSTs 1 protein was added into the

192 reaction system and then was incubated at $5^{\circ} \mathrm{C}, 15^{\circ} \mathrm{C}, 25^{\circ} \mathrm{C}, 35^{\circ} \mathrm{C}, 45^{\circ} \mathrm{C}$, and $60^{\circ} \mathrm{C}$ for $15 \mathrm{~min}$.

193 To determine the effect of $\mathrm{pH}$ on the activity of the purified rEoGSTs1protein, Glutathione S-

194 transferase (GSH-ST) assay kit (Colorimetric method) (Cat. No. A004, Nanjing Jiancheng

195 Bioengineering Institute, Nanjing, Jiangsu, China) was used, following the manufacturer's

196 protocol. The $\mathrm{pH}$ of the reaction system was adjusted with PBS to 5.0, 6.0, 7.0, 8.0, and 9.0.

\section{Data processing}

198 The EoGSTs 1 full-length cDNA was assembled from the DNA fragments using Seqman 7.1.0

199 software (DNAStar, Madison, WI, USA). Homology analysis of EoGSTS1 protein sequences in

200 the NCBI database was performed using BLAST (Johnson et al., 2008). The physical and

201 chemical properties of the EoGSTS1 protein were analyzed using software tools provided in the

202 ExPASy-ProParam website (http://www.expasy.org), and cluster analysis was performed using

203 MEGA 6.0 (Tamura et al., 2013). Clustal Omega (Sievers et al., 2011) was used in amino acid

204 sequence alignment of EoGSTS1 and the GSTs of four other insects of order Hemiptera. The

205 secondary structure of EoGSTS1 was predicted by CLC Genomics Workbench 11.0.1 (CLC Bio,

206 Aarhus, Denmark), whereas the three-dimensional (3D) structure was predicted using I-TASSER

207 software (Roy, Kucukural \& Zhang, 2010). The functional domains were predicted based on the

208 amino acid sequence deduced from the nucleotide sequence of the EoGSTs 1 gene by searching

209 the conserved domain database (CDD) in the NCBI database (Marchler-Bauer et al., 2006).

210 Phylogenetic reconstruction of the GSTs was performed using the maximum likelihood (ML) 
211 method and Bayesian inference (BI) with the assistance of iqtree 1.6.1 (Nguyen et al., 2015) and 212 MrBayes 3.2 (Ronquist et al., 2012).

213

214 RESULTS

215 Detection results of total RNA

216 Both the 28S RNA and 18S RNA bands were observed as distinct bands (Fig. 1), suggesting that 217 the extracted RNAs were of good quality. The OD260/280 ratio of the RNA was 1.92, indicating 218 that the collected RNA was of high purity with no degradation.

219 Amplification of the full-length cDNA

220 The 5' end of the EoGSTs 1 cDNA fragment obtained by 5' RACE was 223 bp in length. The 221 middle fragment of the EoGSTs 1 amplified by intermediate fragment PCR was 480 bp in size.

222 The 3 ' end of the EoGSTs 1 cDNA obtained by 3' RACE was 431 bp in length (Fig. 2A-C). The 223 full-length cDNA of EoGSTs 1 was an 841-bp sequence obtained through sequence assembly of 224 the three DNA fragments; its coding region is 624-bp long, encoding a total of 207 amino acids, 225 including the start codon ATG and the stop codon TGA (Dataset S1). The noncoding region at 226 the $5^{\prime}$ end is $99 \mathrm{bp}$ in length, and the $3^{\prime}$ end noncoding region is $118 \mathrm{bp}$ in length followed by a

227 16-bp poly(A) tail (Fig. 3).

228 Taxonomic identification of EoGST

229 The amino acid sequence of EoGST is highly homologous to GSTs in Sub psaltriayangi 230 (AVC68800.1), Locusta migratoria (AHC08043.1), Daktulosphaira vitifoliae (AUN35388.1), 231 and Leptinotarsa decemlineata (APX61045.1), with a similarity of 53\%, 52\%, 52\%, and 50\%, 232 respectively. 
233 The amino acid sequence of EoGST obtained in small green leafhoppers is shown in Table 2

234 along with 54 other GST sequences belonging to six GST families. Cluster analysis using the

235 adjacency method demonstrated that the EoGST gene is clustered with the Sigma subfamily of

236 GSTs (a high bootstrap value of 99\%), indicating that EoGST is closely related to this particular

237 subfamily (Fig. 4). However, it did not cluster with GSTs in the Delta or Epsilon subfamilies,

238 indicating that it is distantly related to these two subfamilies. Based on these findings and

239 mammalian GST gene nomenclature, the nucleotide sequence of the E. onukii GST (EoGST,

240 cluster-166.0) was initially named as EoGSTS1, and the encoded protein sequence was

241 designated as EoGSTS1.

242 Bioinformatics analysis

243 Physical and chemical properties of the EoGSTS1 protein

244 The molecular weight of EoGSTS1 is $23.68932 \mathrm{kDa}$, with a calculated isoelectric point (IEP) of 245 6.00. The number of negatively and positively charged residues is 30 and 29, respectively. Its N246 terminus begins with methionine, and the half-life of the protein is $30 \mathrm{~h}$. The instability index of 247 the protein in solution is 31.87 , the fat coefficient is 78.26 , and the total average hydrophobicity 248 index is -0.376 . The protein contains a total of 3331 atoms, including 1078 carbon atoms, 1662

249 hydrogen atoms, 276 nitrogen atoms, 305 oxygen atoms, and 10 sulfur atoms. It consists of 20 250 different types of amino acids, among which the top three are alanine (Ala, A), lysine (Lys, K), 251 and glutamic acid (Glu, E), with respective counts of $19(9.2 \%), 19(9.2 \%)$, and $16(7.7 \%)$. The 252 rarely occurring amino acids included Cys $(\mathrm{C})$ and His $(\mathrm{H})$, with counts of $2(1 \%)$ and $1(0.5 \%)$, 253 respectively (Table 3).

254 EoGSTS1 protein sequence alignment 
255 The catalytic domain of the protein contains 69 amino acid residues, as revealed in the SMART 256 software analysis (Letunic et al., 2014). Comparison of the protein sequences of EoGSTS1 and 257 the GSTs of four other insects of order Hemiptera using Clustal Omega (Fig. 5) revealed the 258 existence of multiple conserved domains.

259

260

261

262

263

264 265 266 267 268 269 270 271 272 273 274 275 277

276 The TM-score, which represents the structural similarity between the target sequence

\section{Analysis of the EoGSTS1 protein structure}

Based on its protein sequence, neither signal peptide nor transmembrane helix domains are present in the protein, but four potentially linear antigenic epitopes may exist in the protein sequence (amino acids 31-51, 81-88, 112-123, and 169-180).

The EoGSTS1 protein contains nine $\alpha$ helices, two $\beta$ sheets with a protein kinase $\mathrm{C}$ phosphorylation site, and one N-glycosylation site (Fig. 6). The protein belongs to the superfamily of GSTs and shares sequence similarities with GSTs in other insects (Fig. 7).

The protein sequence of EoGSTS1 contains two Asn-X-Ser/Thr motifs, one of which is an Nglycosylation site. The protein sequence also contains eight other potential phosphorylation sites: four serine phosphorylation sites located at positions 95, 118, 152, and 166 in the peptide chain; two threonine phosphorylation sites located at positions 47 and 125 in the peptide chain; and two tyrosine phosphorylation sites located at positions 148 and 188 in the peptide chain (Table 4).

The 3D structure of the EoGSTS1 protein was predicted using the Blattella germanica GST (BgGST) protein (PDB ID: 4Q5R) as reference (as shown in Fig. 8, the C-terminus is denoted in red and the N-terminus in blue). The C-terminus is composed of 207 amino acids, and the Nterminus contains 204 amino acids. The C-score of the protein structural comparison is 1.21 , indicating that it is highly similar to 4Q5R in terms of protein folding and secondary structure. (EoGSTS1) and the template protein sequence (BgGST), is $0.88 \pm 0.07$.

Peer) reviewing PDF | (2019:03:35500:2:0:NEW 19 Jul 2019) 


\section{Phylogenetic analysis}

279 The phylogenetic tree of the full-length EoGSTS1 protein sequence and GST sequences of 280 insects from five other orders, including Hemiptera, Orthoptera, Coleoptera, Odonata, and 281 Hymenoptera (Table 5), were constructed using BI phylogenetic analysis and an ML-based 282 method. The topological structures of the phylogenetic trees generated using either ML or BI 283 displayed substantial similarities (Fig. 9). Cluster analysis indicated that the EoGSTS1 is 284 clustered with known insect GSTs of order Hemiptera but not with GSTs from insects of order 285 Odonata or Hymenoptera. These results suggest that E. onukii Matsuda is most closely related to 286 insects of order Hemiptera and relatively closely related to those in order Orthoptera but distantly related to insects of orders Hymenoptera, Coleoptera, and Odonata.

\section{Expression of the rEoGSTs1 protein}

The recombinant expression plasmid pCzn1-EoGSTs1-target was transformed into E. coli. Arctic

Express and the pCzn1/EoGSTs1 fusion protein was successfully expressed with the induction of 291 IPTG. SDS-PAGE analysis showed that rEoGSTs1 was expressed in the supernatant and mainly occurred in a soluble form (Fig. 10A). Western blotting revealed a specific band in the corresponding position, which indicated that this band is the target band (Fig. 10B). The concentration of the target protein that was determined by the BCA method was $1.2 \mathrm{mg} / \mathrm{mL}$.

\section{Enzymatic analysis of EoGSTS1}

The kinetic data of EoGSTS1 showed that the rEoGSTs1 protein could catalyze CDNB with Km of $0.21 \pm 0.06 \mathrm{mmol} / \mathrm{L}$ and $V \max$ of $14.02 \pm 1.40 \mu \mathrm{mol} / \mathrm{min} \cdot \mathrm{mg}$ (Fig. 11A). At different temperatures, the specific activity of EoGSTS1 initially gradually increased, and then decreased after reaching the highest value at $25^{\circ} \mathrm{C}$, and reached the lowest value at $60^{\circ} \mathrm{C}$. The lowest 
301 enzyme activity of EoGSTS1 initially increased and then decreased with increasing pH, peaked

302 at $\mathrm{pH} 7$, and at $\mathrm{pH} 5$, the enzyme activity was $73.67 \%$ of that at $\mathrm{pH} 7$ (Fig. 11C).

303

304 DISCUSSION

305 GSTs represent a superfamily of genes that are widely present in many organisms and play

306 critical roles in the resistance to foreign substances in insects. In this study, we used

307 transcriptome analysis to screen overexpressed genes induced by thiamethoxam at the early stage

308 of induction. Based on the results, the cDNA of EoGSTs 1 cluster-166.0 was selected, and its

309 full-length cDNA was amplified by qPCR. The end products showed that the full-length cDNA

310 sequence of EoGSTS1 was 841 bp, with a 624-bp coding region that is predicted to generate a

311 protein consisting of 207 amino acids.

312 The results from the homology search and cluster analysis suggest that the EoGSTS1 protein is

313 highly similar to Sub psaltriayangi (AVC68800.1) GST and Locusta migratoria GST

314 (AHC08043.1) and clustered with the GSTs in the Sigma subfamily with stronger support

315 (bootsrap value $>90 \%$ ). Thus, it is believed to belong to the Sigma GST gene subfamily, which

316 coincides with previous findings that the Sigma subfamily of GSTs is involved in chemical

317 resistance in other insects. For example, Zhou et al. (2012) reported that the upregulation of

$318 L s G S T s 2$ gene expression (Sigma subfamily) can be induced by cypermethrin, chlorpyrifos, and

319 fipronil in Laodelphax striatellus. The results from the gene expression study of GST by You et

320 al. showed that PxGSTs1 (another gene in the Sigma subfamily) was significantly upregulated in

321 the resistant strain of Plutella xylostella (You et al., 2015). In the present study, the expression of

322 EoGSTS 1 in the chemically induced group of small green leafhoppers was 6.6538 times that of 
323 the untreated group; therefore, we believe that EoGSTS1 plays an important role in resistance to

324 thiamethoxam in small green leafhoppers.

325 The instability index of the EoGSTS1 protein in solution is below the threshold of 40, and the 326 average hydrophobicity is a negative value, indicating that the protein is a stable hydrophilic 327 protein (Nie, Wu \& Zhang, 2006; Wanyonyi et al., 2011). Using SignalP 4.1 and subcellular

328 localization analysis, we found that the protein lacks sequences that direct subcellular 329 localization such as signal peptides, lysosomes, peroxidase, or mitochondria. There are no 330 transmembrane domains in EoGSTS1. Therefore, we conclude that EoGSTS1 is a 331 nontransmembrane GST protein located in the cytoplasm with a single functional structure (Li et 332 al., 2018).

333 Functional domain prediction based on the protein structure of EoGSTS1 showed that it contains 334 a GST conserved domain and belongs to the protein superfamily. It consists of an N-terminal 335 domain starting with a methionine and a C-terminal domain with multiple $\alpha$ helices and $\beta$ sheets 336 dispersing throughout the structure. These motifs play an important role in linking polypeptides 337 together and forming the protein structure (Sun, 1994). Multiple sites for potential 338 phosphorylation also exist in the protein sequence, which can be divided into three types, with 339 serine phosphorylation as the major one. Phosphorylation site predictions can provide insights 340 into the important biological processes occurring in E. onukii such as cell growth and 341 development, signal transduction, and gene expression. Proteins participate in various essential 342 biological activities in organisms, including signal transduction, enzyme catalysis, and cellular 343 transportation $(W u, 2010)$. Therefore, the 3D structural information of a protein can be very

344 valuable for its related biological or medical studies such as configuring the structural and

345 functional composition of the protein and designing protein-targeted drug molecules (Kuhlman et 
346 al., 2003). In the present study, we used the threading method to predict the 3D structure of

347 EoGSTS1. The results demonstrated that EoGSTS1 in 3D is highly similar to that of the 4Q5R

348 protein from the German cockroach Blattella germanica. The C-score of the compared proteins

349 is $>-5$ and $<2$, and the TM-score is $>0.5$ (Yang \& Zhang, 2015; Xu \& Zhang, 2010), indicating

350 that the prediction model is sound with correct topology and high reliability in terms of quality

351 assessment.

352 Using BLAST alignment, we established that the amino acid sequence encoded by EoGSTs 1 is

353 highly similar to that of Sub psaltriayangi, but its similarities with insects belonging to orders

354 Orthoptera, Coleoptera, Odonata, and Hymenoptera did not show notable differences,

355 suggesting that GSTs are not highly conserved across different orders. The EoGSTS1 clusters

356 with a known insect GST in order Hemiptera in ML-based and BI phylogenetic trees; however,

357 within that gene cluster, EoGSTS1 forms another branch with Cicadidae GST, indicating a close

358 genetic association between the two. However, its genetic relationships with GSTs in insects that

359 are not in order Hemiptera appear to be distantly related, as it is completely separated in the

360 phylogenetic tree. This result further verifies the close genetic association between EoGSTS1

361 and the known GST gene in order Hemiptera and the conservation of the GST genes within order

362 Hemiptera.

363 The target protein was purified by Ni affinity chromatography, the results of SDS-PAGE

364 detection and western blot detection coincided with prediction results of the molecular weight of

365 protein $(23.68932 \mathrm{kDa})$, indicating that the expression product had not been extensively

366 processed and modified. The determination of enzyme activity showed that the specific activity

367 of rEoGSTs 1 protein reached the highest value at $25^{\circ} \mathrm{C}$ and a $\mathrm{pH}$ of 7 , which is similar to the

368 results of glutathione transferase in silkworm (Yamamoto et al., 2006). CNDB is a kind of 
369 insoluble and poisonous chemical compound that has high reactivity with many GST isoforms;

370 therefore, it is often used as a model substrate to detect whether GSTs have detoxification

371 activity (Tan et al., 2014; Deponte, 2013). In this study, the kinetic parameters of EoGSTS1

372 showed that it has catalytic activity on the model substrate CDNB, and compared to the results of

373 the activity of BmGSTD in silkworm (Yamamoto et al., 2012), Vmax of the EoGSTS1 protein is

374 higher than that of BmGSTD, which indicates that rEoGSTs1 protein has good detoxification

375 function. Together with the differential gene profiling results, we propose that EoGSTS1 plays

376 an important role in the detoxification of E. onukii to thiamethoxam.

377

378 CONCLUSIONS

379 In this study, the full-length cDNA of the E. onukii GST gene EoGSTs 1 was successfully

380 amplified by qPCR. EoGSTS1 belongs to the Sigma subfamily of GSTs and is a stable

381 hydrophilic protein located in the cytoplasm and a nontransmembrane GST protein with a single

382 functional structure. The EoGSTS1 protein has multiple motifs of $\alpha$ helices and $\beta$ sheets

383 distributed throughout its $\mathrm{N}$ - and C-termini. The protein sequence indicates the existence of

384 multiple potential phosphorylation sites, with serine phosphorylation sites as the major type. The

$3853 \mathrm{D}$ structure of the EoGSTS1 protein is highly similar to that of 4Q5R, a GST protein in the

386 German cockroach B. germanica. EoGSTS1 is closely related to insect GSTs of order Hemiptera

387 but is distantly related to GSTs of insects of order Blattodea. The results of recombinant

388 expression and purification of EoGSTS1 in vitro and the enzyme activity assay of purified

389 protein show that EoGSTS1 possesses detoxification activity.

390

391 REFERENCES 
392 Chelvanayagam G, Parker MW, Board P. 2001. Fly fishing for GSTs: a unified nomenclature 393 for mammalian and insect glutathione transferases. Chemico-biological interactions 133:

394

395

396

397

398

399

400

401

402

403

404

405

406

407

408

409

410

411

412

413

414 $256-260$

Deponte M. 2013. Glutathione catalysis and the reaction mechanisms of glutathione-dependent enzymes. Biochimica et Biophysica Acta (BBA)-General Subjects 1830(5): 3217-3266

Enayati AA, Ranson H, Hemingway J. 2005. Insect glutathione transferases and insecticide resistance. Insect Molecular Biology 14(1): 3-8

Fu JY, Han BY, Xiao Q. 2014. Mitochondrial COI and 16sRNA evidence for a single species hypothesis of E. vitis, J. formosana and E. onukii in East Asia. PloS One 9(12): e115259

Johnson M, Zaretskaya I, Raytselis Y, Merezhuk Y, McGinnis S, Madden TL. 2008. NCBI BLAST: a better web interface. Nucleic acids research 36(suppl_2): W5-W9

Hazarika LK, Bhuyan M, Hazarika BN. 2009. Insect pests of tea and their management. Annual Review of Entomology 54: 267-284

Kuhlman B, Dantas G, Ireton GC, Varani G, Stoddard BL, Baker D. 2003. Design of a novel globular protein fold with atomic-level accuracy. Science 302(5649): 1364-1368

Letunic I, Doerks T, Bork P. 2015. SMART: recent updates, new developments and status in 2015. Nucleic Acids Research 43(D1): D257-D260

Li LD, Wang DF, Li HL, Zhang H, Zeng MS, Wu GY. 2018. Cloning and bioinformatics of CYP6A14 gene from Empoasca flavescens (Hemiptera: cicadas). Acta Tea Sinica 59(1): 15

Li S, Su L, Li BL, Li YP, Li GW, Wu JX. 2018. cDNA cloning, prokaryotic expression and enzymatic characteristics of the glutathione S-transferase GmolGST6 in Grapholita molesta (Lepidoptera: Tortricidae). Acta Entomologica Sinica 61(4): 398-409 
415 Marchler-Bauer A, Anderson JB, Derbyshire MK, DeWeese-Scott C, Gonzales NR, Gwadz 416 M, Hao L, He S, Hurwitz DI, Jackson JD, Ke Z, Krylov D, Lanczycki CJ, Liebert CA,

417

418

419

420

421

422

423

424

425

426

427

428

429

430

431

432

433

434

435

436

437

Liu C, Lu F, Lu S, Marchler GH, Mullokandov M, Song JS, Thanki N, Yamashita RA, Yin JJ, Zhang D, Bryant SH. 2006. CDD: a conserved domain database for interactive domain family analysis. Nucleic acids research 35(suppl_1): D237-D240

Mu D, Cui L, Wang MX, Liu LF, Yu XP, Zhang QH, Han BY. 2012. Behavioral responses for evaluating the attractiveness of specific tea shoot volatiles to the tea green leafhopper, Empoaca vitis. Insect Science 19(2): 229-238

Nie L, Wu G, Zhang W. 2006. Correlation between mRNA and protein abundance in Desulfovibrio vulgaris: a multiple regression to identify sources of variations. Biochemical and Biophysical Research Communications 339(2): 603-610

Niu YQ, Wang MX, Cui L, Ye HX, Pan C, Han BY. 2015. Control of the tea green leafhopper via volatile compounds of rosemary: the potential for further development of a Push-Pull strategy. Acta Ecologica Sinica 35(7): 2380-2387

Nguyen LT, Schmidt HA, von Haeseler A, Minh BQ. 2015. IQ-TREE: a fast and effective stochastic algorithm for estimating maximum likelihood phylogenies. Molecular Biology and Evolution 32(1): 268-274

Qin D, Zhang L, Xiao Q, Dietrich C, Matsumura M. 2015. Clarification of the identity of the tea green leafhopper based on morphological comparison between Chinese and Japanese specimens. PloS One 10(9): e0139202

Ronquist F, Teslenko M, van der Mark P, Ayres DL, Darling A, Höhna S, Larget B, Liu L, Suchard MA, Huelsenbeck JP. 2012. MrBayes 3.2: efficient bayesian phylogenetic inference and model choice across a large model space. Systematic Biology 61(3): 539-542

Peer) reviewing PDF | (2019:03:35500:2:0:NEW 19 Jul 2019) 
438 Roy A, Kucukural A, Zhang Y. 2010. I-tasser: a unified platform for automated protein $439 \quad$ structure and function prediction. Nature Protocols 5(4): 725-38

440 Saha D, Mukhopadhyay A. 2013. Insecticide resistance mechanisms in three sucking insect 441 pests of tea with reference to North-East India: an appraisal. International Journal of $442 \quad$ Tropical Insect Science 33(1): 46-70

443 Sievers F, Wilm A, Dineen D, Gibson TJ, Karplus K, Li W, Lopez R, McWilliam H, 444 Remmert M, Söding J, Thompson JD, Higgins DG. 2011. Fast, scalable generation of 445 446 high-quality protein multiple sequence alignments using Clustal Omega. Molecular Systems Biology 7(1): 539

Sun ZR. 1994. The classification of peptide connecting $\alpha$-helices and $\beta$-strands in proteins. Journal of Tsinghua University 34: 58-62

Tamura K, Stecher G, Peterson D, Filipski A, Kumar S. 2013. MEGA6: molecular 450 451 evolutionary genetics analysis version 6.0. Molecular Biology and Evolution 30(12): 27252729

Tan X, Hu XM, Zhong XW, Chen QM, Xia QY, Zhao P. 2014. Antenna-specific glutathione S-transferase in male silkmoth Bombyx mori. International journal of molecular sciences 15(5): 7429-7443

Wang NW. 2004. Studies on the threshold and pesticide resistance comparison of green leafhopper Empoasca vitis Göthe. Master Thesis. Fuzhou: Fujian Agriculture and Forestry University

Wanyonyi SS, Sharp JA, Khalil E, Lefevre C, Nicholas KR. 2011. Tammar wallaby mammary cathelicidins are differentially expressed during lactation and exhibit 
460

461

462

463

464

465

466

467

468

469

470

471

472

473

474

475

476

477

478

479

480

481

482

antimicrobial and cell proliferative activity. Comparative Biochemistry and Physiology Part A: Molecular \& Integrative Physiology 160(3): 431-439

Wu JZ. 2010. The study on applying parallel ant colony optimization to protein structure prediction. Suzhou : Suzhou University 1

Wu YC, Xu ZP, Shao XS, Cheng JG, Li Z. 2016. Toxicity of cycloxaprid to Aphis craccivora (Koch) and its effects on detoxification enzymes. Chinese Journal of Pesticide Science 18(6): $710-716$

Xu J, Zhang Y. 2010. How significant is a protein structure similarity with TM-score $=0.5$. Bioinformatics 26(7): 889-895

Yamamoto K, Usuda K, Kakuta Y, Kimura M, Higashiura A, Nakagawa A, Aso Y, Suzuki M. 2012. Structural basis for catalytic activity of a silkworm Delta-class glutathione transferase. Biochimica et Biophysica Acta (BBA)-General Subjects 1820(10): 1469-1474

Yamamoto K, Zhang PB, Banno Y, Fujii H. 2006. Identification of a sigma-class glutathioneS-transferase from the silkworm, Bombyx mori. Journal of Applied Entomology 130(9-10): $515-522$

Yang J, Zhang Y. 2015. Protein structure and function prediction using I-TASSER. Current Protocols in Bioinformatics 52(1): 5.8.1-5.8.15

Yu QY, Fang SM, Zuo WD, Zhang Z, Lu C. 2010. Molecular cloning, sequence analysis and tissue expression characterization of glutathione s-transferase gene bmgstz1 in bombyx mori. Acta Entomologica Sinica 53(10): 1061-1068

You Y, Xie M, Ren N, Cheng X, Li J, Ma X, Zou M, Vasseur L, Gurr GM, You M. 2015. Characterization and expression profiling of glutathione S-transferases in the diamondback moth, Plutella xylostella (L.). BMC genomics 16(1): 152-159 
483 Zhan MK, Fang SM, Chen M, Wang B, Li ZZ. 2012. Screening for a highly virulent

484 entomogenous fungal strain to Empoasca vitis (Homoptera: Cicadellidae) and its field

485 efficacy. Chinese Journal of Biological Control 28(1): 41-46

486 Zhang GF, Li LL, Li BJ, Wang KY, Xia XM. 2014. Resistance detection and synergism of

487 enzyme inhibitors on neonicotinoids to Aphis gossypii in Shandong province. Chinese

488 Journal of Pesticide Science 16(6): 673-680

489 Zhang Z, Chen Z. 2015. Non-host plant essential oil volatiles with potential for a 'push-pull'

490 strategy to control the tea green leafhopper, Empoasca vitis. Entomologia Experimentalis et

$491 \quad$ Applicata 156(1): 77-87

492 Zhou C, Han ZJ. 2017. Aquaporin gene cloning and its possible contribution to insecticide

493 metabolism in laodelphax striatellus. Journal of Nanjing Agricultural University 40(6):

$494 \quad 1014-1022$

495 Zhou WW, Li XW, Quan YH, Cheng J, Zhang CX, Gurr G, Zhu ZR. 2012. Identification

496 and expression profiles of nine glutathione S-transferase genes from the important rice

497 phloem sap-sucker and virus vector Laodelphax striatellus (Fallén) (Hemiptera:

498 Delphacidae). Pest Management Science 68(9): 1296-1305

499 
Table $\mathbf{1}$ (on next page)

Primers and sequences 
1

2

3

Table 1 Primers and sequences

\begin{tabular}{ll}
\hline Primer & Sequence $\left(5^{\prime}\right.$ to $\left.3^{\prime}\right)$ \\
\hline rGST-R1 & CTCCTGCCTTACCCTCGATCTCAAGAAT \\
rGST-R2 & CAGGCCATTCACCCCATTTGACTCTG \\
mGST $-\mathrm{F}$ & GGGCTTGGAGAACCCATAAGATT \\
mGST $-\mathrm{R}$ & GATATCTGACCCGTTCATGTTGC \\
rGST $-\mathrm{F} 1$ & GAGAGGGGAGTTGGCGAAATACTACTACGA \\
rGST $-\mathrm{F} 2$ & GGCGAAATACTACTACGAGCGTGATGAAGAG \\
\hline
\end{tabular}

4

5 
Table 2 (on next page)

GST genes of different insect species and GenBank accession numbers 
Table 2 GST genes of different insect species and GenBank accession numbers

\begin{tabular}{|c|c|c|c|}
\hline Types & Species & Gene code & Accession number \\
\hline \multirow{9}{*}{ Delta } & Tenebrio molitor & TmGSTD & AIL23532.1 \\
\hline & Locusta migratoria & LmGSTD & ADR30117.1 \\
\hline & Bombyx mori & BmGSTD & BAD60789.1 \\
\hline & Culex pipiens & CpGSTD & AEW07374.1 \\
\hline & Plutella xylostella & PxGSTD & BAJ10978.1 \\
\hline & Lasioderma serricorne & LsGSTD & AUO28661.1 \\
\hline & Chilo suppressalis & CsGSTD & AKS40338.1 \\
\hline & Cnaphalocrocis medinalis & CmGSTD & AIL29308.1 \\
\hline & Spodoptera litura & SIGSTD & AIH07596.1 \\
\hline \multirow{9}{*}{ Epsilon } & Drosophila willistoni & DwGSTE & XP_002068808.1 \\
\hline & Spodoptera exigua & SeGSTE & AHB18378.1 \\
\hline & Bombyx mori & BmGSTE & NP_001108460.1 \\
\hline & Anopheles funestus & AfGSTE & AHC31033.1 \\
\hline & Cnaphalocrocis medinalis & CmGSTE & AIL29313.1 \\
\hline & Spodoptera litura & SIGSTE & AIH07589.1 \\
\hline & Aedes aegypti & AaGSTE & NP_001345908.1 \\
\hline & Bicyclus anynana & BaGSTE & AON96571.1 \\
\hline & Anopheles cracens & AcGSTE & ACY95463.1 \\
\hline \multirow{9}{*}{ Theta } & Alitta succinea & AsGSTT & ABQ82132.1 \\
\hline & Tenebrio molitor & TmGSTT & AIL23552.1 \\
\hline & Mus musculus & MmGSTT & CAA66666.1 \\
\hline & Carassius auratus & CaGSTT & ABW96271.1 \\
\hline & Cyprinus carpio & CcGSTT & BAS29977.1 \\
\hline & Channa punctata & CpGSTT & ABY83769.1 \\
\hline & Procambarus clarkii & PcGSTT & AXR98486.1 \\
\hline & Andrias davidianus & AdGSTT & AYG85510.1 \\
\hline & Medicago truncatula & MtGSTT & AET05000.1 \\
\hline \multirow{9}{*}{ Omega } & Sus scrofa & SsGSTO & AAF71994.2 \\
\hline & Halocynthia roretzi & HrGSTO & BAD77935.1 \\
\hline & Schistosoma mansoni & SmGSTO & AAO49385.1 \\
\hline & Tenebrio molitor & TmGSTO & AIL23546.1 \\
\hline & Perna viridis & PvGSTO & AGN03944.1 \\
\hline & Tigriopus japonicus & TjGSTO & ACE81246.1 \\
\hline & Cyprinus carpio & CcGSTO & BAS29980.1 \\
\hline & Kryptolebias marmoratus & KmGSTO & AEM65182.1 \\
\hline & Spodoptera exigua & SeGSTO & AHB18379.1 \\
\hline Zeta & Brassica napus & BnGSTZ & AAO60042.1 \\
\hline
\end{tabular}




\begin{tabular}{lll} 
Arabidopsis thaliana & AtGSTZ & AAO60039.1 \\
Tigriopus japonicus & TjGSTZ & ACE81250.1 \\
Tenebrio molitor & TmGSTZ & AIL23553.1 \\
Panonychus citri & PcGSTZ & AFD36889.1 \\
Azumapecten farreri & AfGSTZ & ADD82544.1 \\
Vibrio sinaloensis & VsGSTZ & EGA70514.1 \\
Tetrahymena thermophila & TtGSTZ & EAR89084.1 \\
Cyprinus carpio & CcGSTZ & BAS29981.1 \\
Antheraea pernyi & ApGSTS & ADC32118.1 \\
Bombyx mori & BmGSTS & BAD91107.1 \\
Tenebrio molitor & TmGSTS & AIL23551.1 \\
Chilo suppressalis & CsGSTS & ADD14027.1 \\
Daphnia magna & DmGSTS & AOQ25845.1 \\
Lasioderma serricorne & LsGSTS & AUO28662.1 \\
Operophtera brumata & ObGSTS & KOB58098.1 \\
Mytilus galloprovincialis & MgGSTS & AFQ35985.1 \\
Cnaphalocrocis medinalis & CmGSTS & AIZ46905.1 \\
\hline
\end{tabular}

3

4 
Table 3 (on next page)

The chemical composition of the cloned fragment of EoGSTs1 
Table 3 The chemical composition of the cloned fragment of EoGSTs1

\begin{tabular}{llllllll}
\hline Amino acid & Number & $\begin{array}{l}\text { Proportion } \\
\text { of quantity }\end{array}$ & Mass ratio & Amino acid & Number & $\begin{array}{l}\text { Proportion } \\
\text { of quantity }\end{array}$ & Mass ratio \\
\hline Ala (A) & 19 & $9.20 \%$ & $6.18 \%$ & Lys (K) & 19 & $9.20 \%$ & $10.14 \%$ \\
Arg (R) & 10 & $4.80 \%$ & $6.36 \%$ & Met (M) & 8 & $3.90 \%$ & $4.36 \%$ \\
Asn (N) & 6 & $2.90 \%$ & $2.89 \%$ & Phe (F) & 9 & $4.30 \%$ & $5.43 \%$ \\
Asp (D) & 14 & $6.80 \%$ & $6.80 \%$ & Pro (P) & 12 & $5.80 \%$ & $5.04 \%$ \\
Cys (C) & 2 & $1.00 \%$ & $0.88 \%$ & Ser (S) & 7 & $3.40 \%$ & $2.68 \%$ \\
Gln (Q) & 6 & $2.90 \%$ & $3.20 \%$ & Thr (T) & 8 & $3.90 \%$ & $3.48 \%$ \\
Glu (E) & 16 & $7.70 \%$ & $8.59 \%$ & Trp (W) & 6 & $2.90 \%$ & $4.47 \%$ \\
Gly (G) & 14 & $6.80 \%$ & $3.84 \%$ & Tyr (Y) & 10 & $4.80 \%$ & $6.61 \%$ \\
His (H) & 1 & $0.50 \%$ & $0.57 \%$ & Val (V) & 13 & $6.30 \%$ & $5.56 \%$ \\
Ile (I) & 13 & $6.30 \%$ & $6.22 \%$ & Pyl (O) & 0 & $0.00 \%$ & $0.00 \%$ \\
Leu (L) & 14 & $6.80 \%$ & $6.70 \%$ & Sec (U) & 0 & $0.00 \%$ & $0.00 \%$ \\
\hline
\end{tabular}

3 
Table 4 (on next page)

Predicted phosphorylation sites 
1

2

Table 4 Predicted phosphorylation sites

\begin{tabular}{llllllll}
\hline Position & Sequence & Score & Classification & Position & Sequence & Score & Classification \\
\hline 95 & DEIVSVVDE & 0.986 & ${ }^{*} \mathrm{~S} *$ & 47 & IKPNTPWGK & 0.801 & $* \mathrm{~T}^{*}$ \\
118 & ERKASLKEP & 0.998 & ${ }^{*} \mathrm{~S} *$ & 125 & EPVLTQTVP & 0.597 & $* \mathrm{~T} *$ \\
152 & NGKFSWADV & 0.985 & ${ }^{*} \mathrm{~S} *$ & 145 & ENKGYLANG & 0.932 & $* \mathrm{Y} *$ \\
166 & SDHMSNMNG & 0.546 & $* \mathrm{~S} *$ & 188 & RERVYAIPK & 0.890 & $* \mathrm{Y}^{*}$ \\
\hline
\end{tabular}

3 
Table 5 (on next page)

GST genes of different insect species and GenBank accession numbers 
Table 5 GST genes of different insect species and GenBank accession numbers

\begin{tabular}{|c|c|c|}
\hline Species & Gene code & Accession number \\
\hline Sogatella furcifera & SyGST & AFJ75815.1 \\
\hline Halyomorpha halys & HhGST & XP_014283901.1 \\
\hline Laodelphax striatella & LsGST & AEY80032.1 \\
\hline Nilaparvata lugens & N1GST & XP_022201420.1 \\
\hline Riptortus pedestris & RpGST & BAN21228.1 \\
\hline Cimex lectularius & ClGST & XP_024082892.1 \\
\hline Sogatella furcifera & SfGST & AFJ75815.1 \\
\hline Locusta migratoria & LmGST & AHC08043.1 \\
\hline Schistocerca gregaria & SgGST & AEV89756.1 \\
\hline Leptinotarsa decemlineata & LdGST & APX61045.1 \\
\hline Tribolium castaneum & TcGST & XP_967475.1 \\
\hline Anoplophora glabripennis & AgGST & XP_018560985.1 \\
\hline Tenebrio molitor & TmGST & AIL23548.1 \\
\hline Aethina tumida & AtGST & XP_019878993.1 \\
\hline Agrilus planipennis & ApGST & XP_018334284.1 \\
\hline Blattella germanica & $\mathrm{BgGST}$ & PSN56155.1 \\
\hline Zootermopsis nevadensis & ZnGST & XP_021913534.1 \\
\hline Periplaneta americana & PaGST & AVA17428.1 \\
\hline Apis cerana cerana & AcGST & PBC25817.1 \\
\hline Athalia rosae & ArGST & XP_012268124.1 \\
\hline Copidosoma floridanum & CfGST & XP_014210579.1 \\
\hline Apis florea & AfGST & XP_003694329.2 \\
\hline Apis mellifera & AmGST & XP_026295805.1 \\
\hline Megachile rotundata & MrGST & XP_003703954.1 \\
\hline Microplitis demolitor & MdGST & XP_008550325.1 \\
\hline
\end{tabular}

3 
Figure 1

$1 \%$ gel electrophoresis results of tatol RNA. 


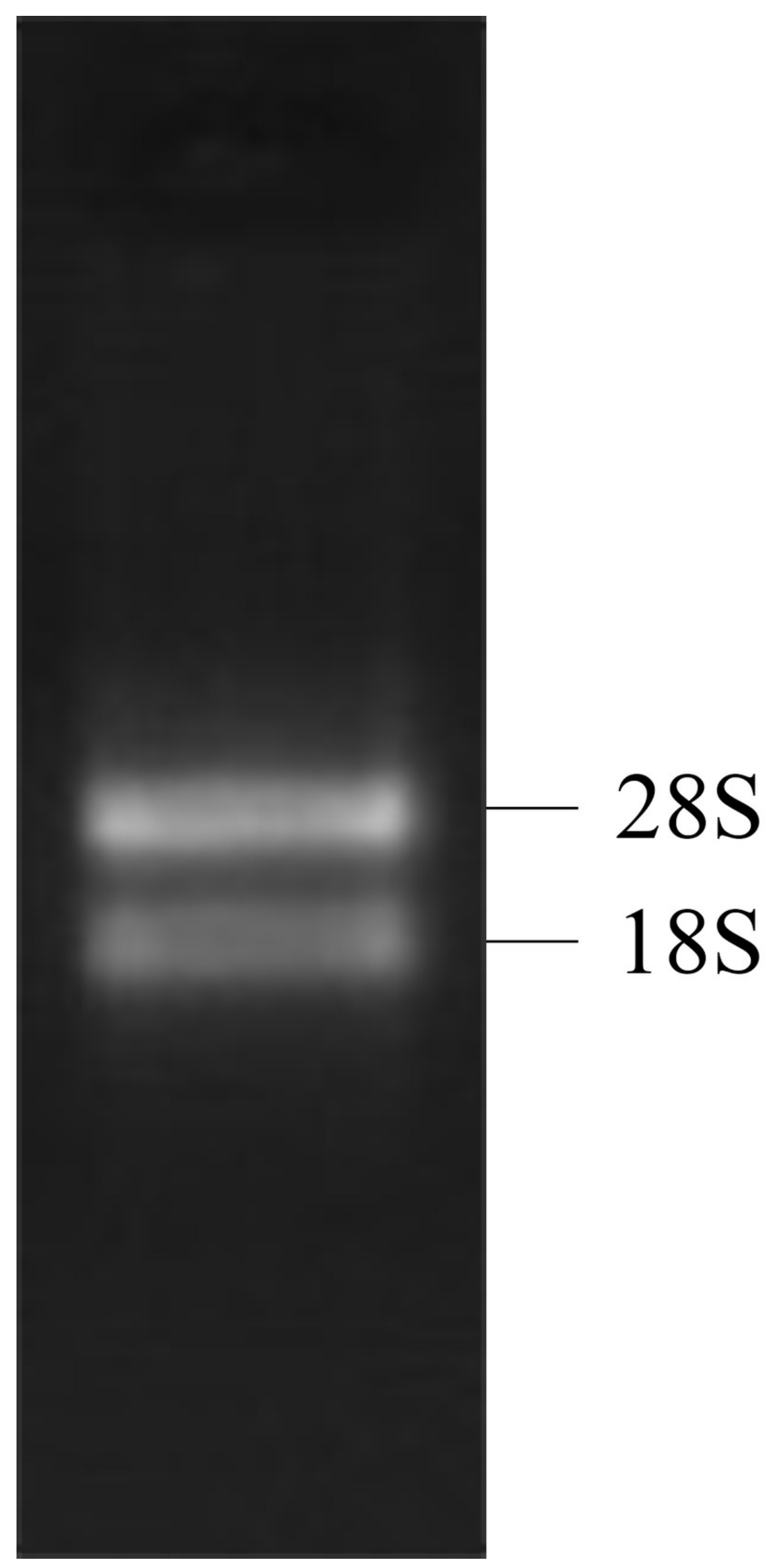




\section{Figure 2}

$1.5 \%$ gel electrophoresis results of amplification products.

A, 5' RACE PCR; B, middle fragment PCR; C, 3' RACE PCR.

A

(bp)

5000

3000

2000

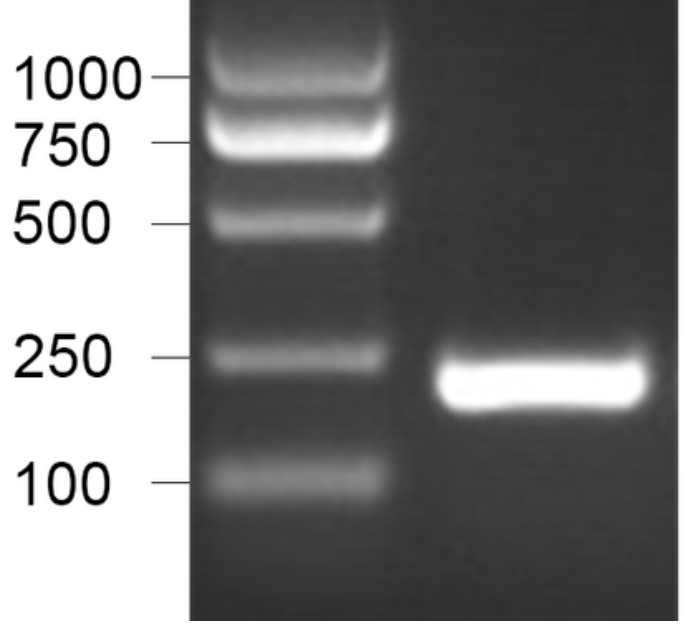

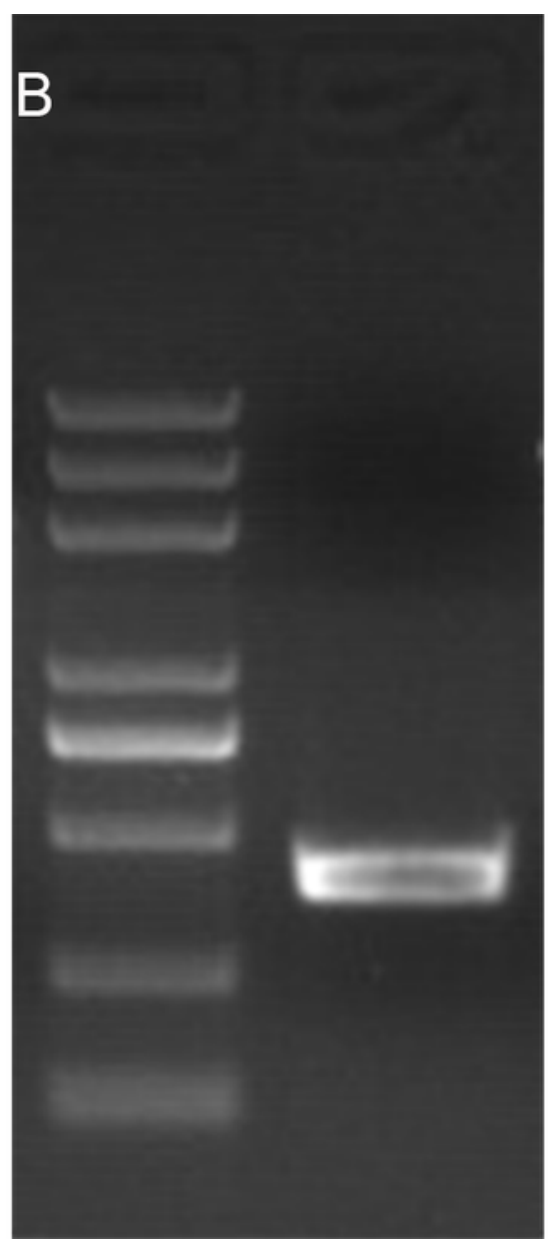

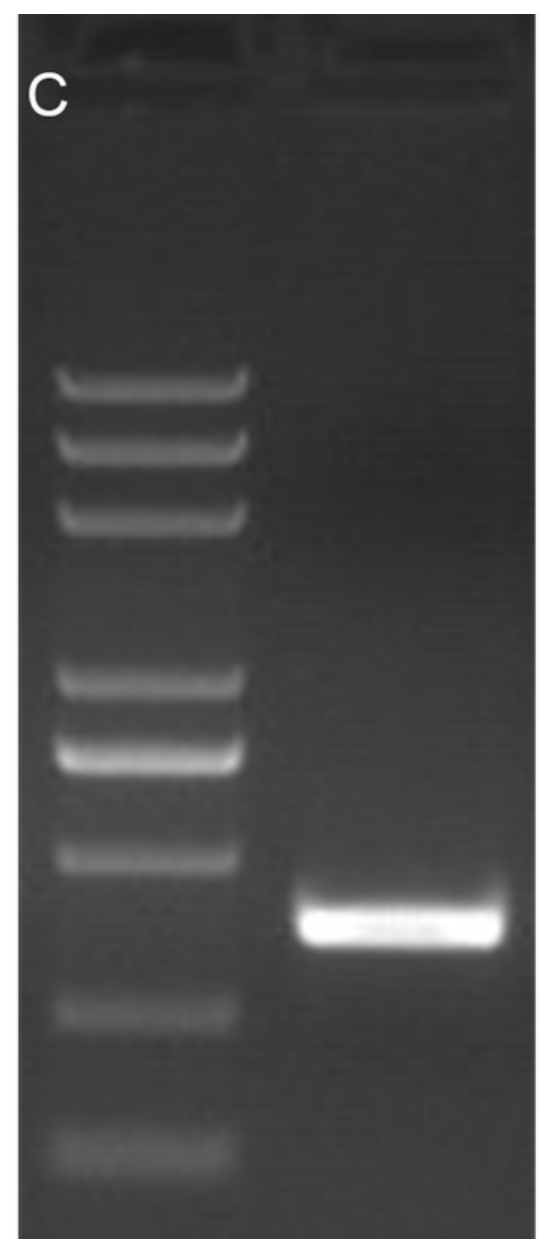


Figure 3

Complete nucleotide sequence encoding E. onukii Matsuda and deduced amino acids of the cloned EoGSTs1.

Start codon (ATG), black bold; Putative polyadenylation signal, underline; Stop codon, black bold with an asterisk; Putative catalytic domain, rectangle; N-linked glycosylation sites, italic bold. 
1

61

1

121

8

181

28

241

48

301

68

361

88

421

108

481

128

541

148

601

168

661

188

721

781

841

GGAATACACAGCATATAGCTAAATCAGTTAGATTACACTGACTATACTTGAGCTTGCAGT GTTGGTTAGTCTTTCATGTACAGTGCATCTAACAGTAACATGGCAGCTAAGTATAAAGTC M $\quad$ A

ACTTATTTCCCTATCATGGGGCTTGGAGAACCCATAAGATTCCTGTTGGCTTACATGGGA \begin{tabular}{lllllll|llllllllllllll}
$T$ & $Y$ & $F$ & $P$ & $I$ & $M$ & $G$ & $L$ & $G$ & $E$ & $P$ & $I$ & $R$ & $F$ & $L$ & $L$ & $A$ & $Y$ & $M$ & $G$ \\
\hline
\end{tabular} GAGGATTTTGAAGACTGCAGAGTCAAATGGGGTGAATGGCCTGACATAAAACCAAATACG \begin{tabular}{|llllllllllllllllllll|}
\hline E & D & F & E & D & C & R & V & K & W & G & E & W & P & D & I & K & P & N & T \\
\hline
\end{tabular}

CCGTGGGGCAAAATGCCGATTCTTGAGATCGAGGGTAAGGCAGGAGTGACCCAGAGTCAA \begin{tabular}{|llllllllllllllllllll|}
\hline P & W & G & K & M & P & I & L & E & I & E & G & K & A & G & V & T & Q & S & Q \\
\hline
\end{tabular}

GCAGTGACCAGGTTCTTGGCCAGACAAGCAGGGCTGTGTGGGGACGGAGCTTGGGAGGAT \begin{tabular}{|llllllllllllllllllllll}
\hline A & V & T & R & F & L & A & R & Q & A & G & L & C & G & D & G & A & W & E & D
\end{tabular}

CTCAAGATTGACGAGATCGTGTCAGTCGTTGATGAATTGAGAGGGGAGTTGGCGAAATAC $\begin{array}{llllllllllllllllllll}L & K & I & D & E & I & V & S & V & V & D & E & L & R & G & E & L & A & K & Y\end{array}$

TACTACGAGCGTGATGAAGAGAGGAAAGCAAGTTTGAAAGAACCAGTTCTCACTCAAACT

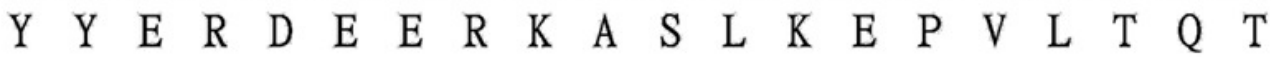

GTTCCATTTTACATGAAGAAAATAAACACTTTGATTCAAGAAAACAAAGGCTACTTGGCT $\begin{array}{llllllllllllllllllll}V & P & F & Y & M & K & K & I & N & T & L & I & Q & E & N & K & G & Y & L & A\end{array}$

AATGGAAAGTTCTCCTGGGCAGATGTGTTCTTTGCAGCGATCAGTGATCACATGAGCAAC $\begin{array}{llllllllllllllllllll}N & G & K & F & S & \text { W } & A & D & V & F & F & A & A & I & S & D & H & M & S & N\end{array}$

ATGAACGGGTCAGATATCACGGCTGACTATCCTCAAGCCAAAGCCCTGCGAGAAAGGGTC $\begin{array}{llllllllllllllllllll}\text { M } & N & G & S & D & \text { I } & \text { T } & \text { A } & \text { D } & \text { Y } & \text { P } & \text { Q } & \text { A } & \text { K } & \text { A } & \text { L } & \text { R } & \text { E } & \text { R } & \text { V }\end{array}$

TATGCCATCCCCAAGATAAAGGCTTGGGTGGACAAACGACCCAAAGATGTCCCCATGTTT

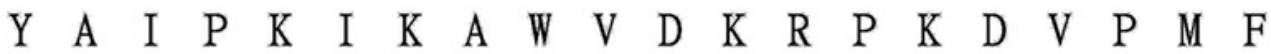

TGAATGCCAAAATAAGACATCTTAAACCTGAGATGTTAACTGAAATTGAAATATTTATCT CACAAAACTAATTGTTCTGCATTAATAAATAAGGTTTAATTCACTA $\underline{A}$ 


\section{Figure 4}

Clustering analysis of GST genes of different insect species based on the neighbouring method.

Numbers on the branch represent the bootstrap value (bootstrap $>70 \%$ ).

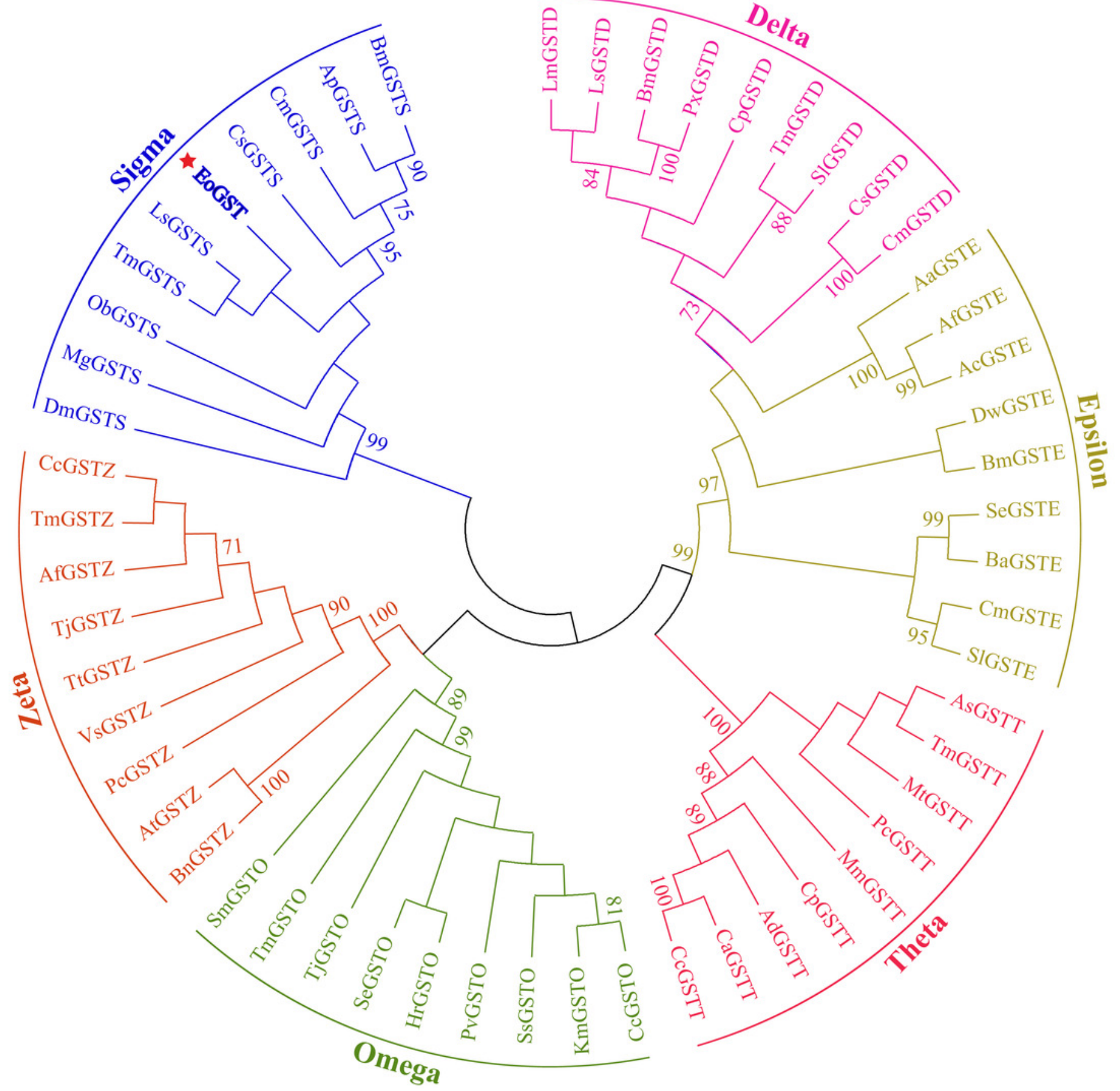




\section{Figure 5}

Comparison of GST amino acid sequence of some insects (Hemiptera).

'*' represents identical amino acid residues, ' - ' represents sequence deletion of RNA at this position, '. ' and ':' represent conservatism of RNA sequence at different degrees, no identifier represents the sequence does not have conservation. 
EOGST MAAKYKVTYFPIMGLGEPIRFLLAYMGEDFEDCRVKWGEWPDIKPNTPWGKMPILEIEGK SyGST MALKYKLTYFDGKGLAEPIRYILSYMGEEFEDDRFTKEEWPLIKPSTPFGKAPVLSVDGK SfGST LsGST -MSTYKLTYFPVTALGEPIRWLMSYLDIKFEDYRFEREQWPSIKPTTPFGQVPVLEIDGK N1GST -MSAYKLTYFPVTALGEPIRWLLSYLDIKFEDYRFEREQWPSIKPTTPFGQVPVLEIDGK -MSGYKLTYFPVTALGEPIRWMMSYLDIKFEDYRFEREQWPSIKPTTPFGQVPVLEIDGK $* * * * * *$ $*$ *****:: : :*:. .*****. :*****.**:*:*:*.: :**

EoGST AGVTQSQAVTRFLARQAGLCGDGAWEDLKIDEIVSVVDELRGELAKYYYERDEERKASLK SyGST Q-LCQSVALTRYLAKKADLVGKDEWEDLHIDMIVDTIGDLRQAIASYYYDPDEESRAAKK SfGST A-VWQSVAISRYFGKKADLAGKDEWESLMIDVIVDTFSDFRLAVGKWFYESDEATKKNLE LsGST V-VWQSVAISRYFGKKADLAGKDEWEALMIDVIVDTFTDFRMAVGKWFYESDEAAKKKLE N1GST S-VWQSVAISRYFGKKADLAGKDEWESLMIDVIVDTFTDFRLAVGKWFYESDEATKKKLE

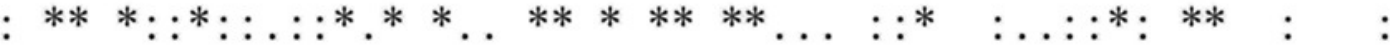

EOGST EPVLTQTVPFYMKKINTLIQENKGYLANGKFSWADVFFAAISDHMSNMNGSDITADYPQA SyGST EPLLNETIPFYMSKFENIANENNGYLANGRLSWADIYLVALSEYMSSIAGTDLLEPYPTL SfGST KPLFETTIPFYLEKFDSKIKENGGFLANGKLSWGDIYFVAVSGYVNHMLGFNMSEKYDNI LsGST IPLFETTVPFYLEKFDSTIKENGGFLANGKLSWGDIFFVAVSGYVNHMLGFNMSDKYENI N1GST KPLLETTVPFYLEKFDSTIKENGGFLANGKLSWGDIYFVATSGYINHMLGFNMSDKYENI

$$
*:: \quad *: * * *: *:: . \quad: * * *: * * * *:: * * *::: \text { * }^{*} *:: .: \text { : }^{*}:: \quad *
$$

EOGST KALRERVYAIPKIKAWVDKRPKDVPMF SyGST TSLKEIVWGIPKIKEWIEKRPKTDI - SfGST KALCEKVSAIPKIKEWIAKCPAGI - - LsGST KALCEKVSAIPKIKEWIDKRPAGI - - N1GST KALCEKVAAIPKIKEWIDKRPAGI - - -

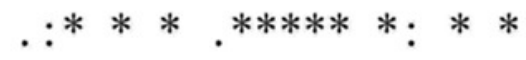




\section{Figure 6}

Predicted secondary structure and annotated functional sites of the EoGSTS1 protein.

The protein kinase $\mathrm{C}$ phosphorylation site is shown in purple and the $\mathrm{N}$-glycosylation site is shown in yellow.

MAAKYKVTYFP I MGLGEP IRF LAYMGEDFEDCRVKWGEWPD I KPNTPWGKMP I LE I EGKAGV
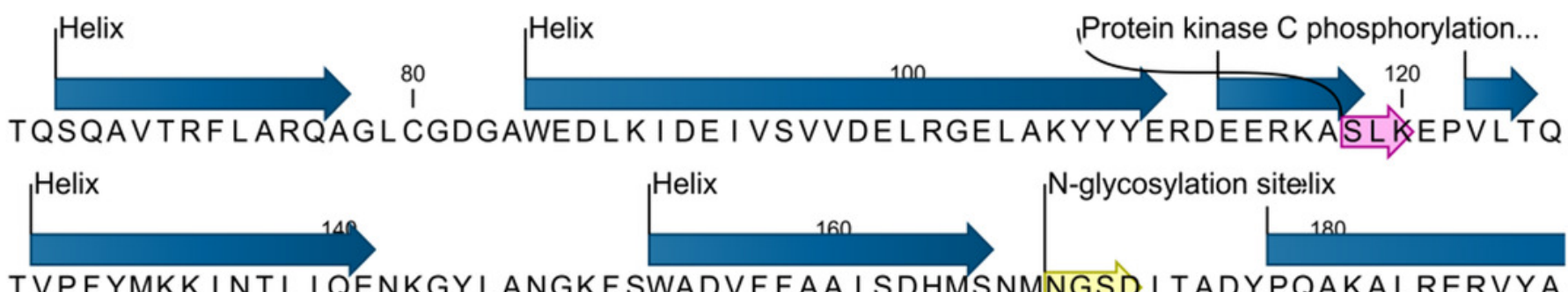

TVPFYMKK I NTL I QENKGYLANGKF SWADVFFAA I SDHMSNMNGSD I TADYPQAKALRERVYA Helix

$\Rightarrow 200$

I PK I KAWVDKRPKDVPMF 


\section{Figure 7}

Prediction of the functional domains of the EoGSTS1 protein.

Small triangle: conservative character or amino acid oftheconservedsites, specific hits:

specific hits domains, non-specific hits: non-specific hits domains, superfamilies:

superfamilies that corresponds to the above-mentioned matching domains.

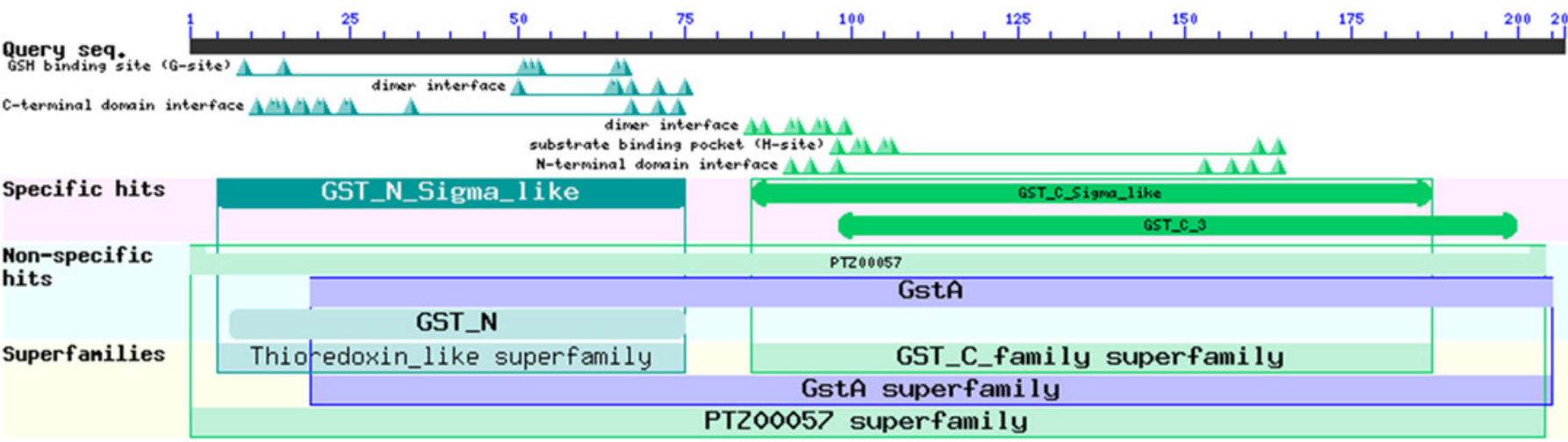




\section{Figure 8}

Figure 8 Predicted 3D structure and main chain interface structure of the EoGSTS1 protein.

A: Predicted 3D structure of the EoGSTs1 protein of E. onukii Matsuda. B: Superimposed prediction model and native cartoon structures of E. onukii Matsuda EoGSTs1 and Blattella germanica GST. Rainbow structure represents E. onukii Matsuda EoGSTs1. Purple line represents the alpha carbon backbone trace of $B$. germanica GST.
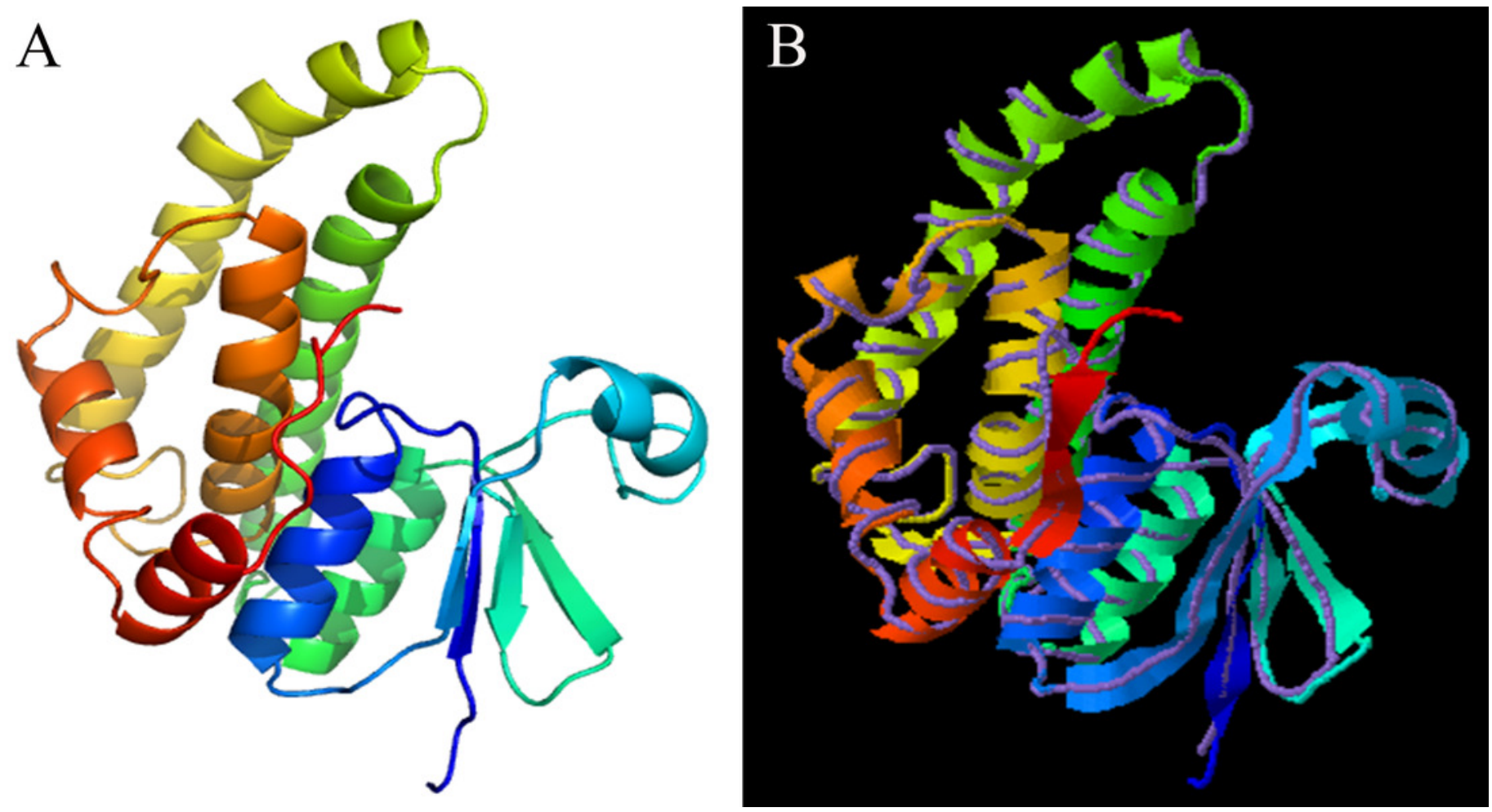
Figure 9

The phylogenetic tree was constructed with ML (best model: $L G+I+G 4$ ) and $B I$ (best model: $L G+I+G,-I n L=-7163.4499)$ methods based on the GST genes of different insects.

Numbers on the branch indicate the ML bootstrap values (>70\%), whereas Bayesian posterior possibilities (>90\%) are shown under the branch. 


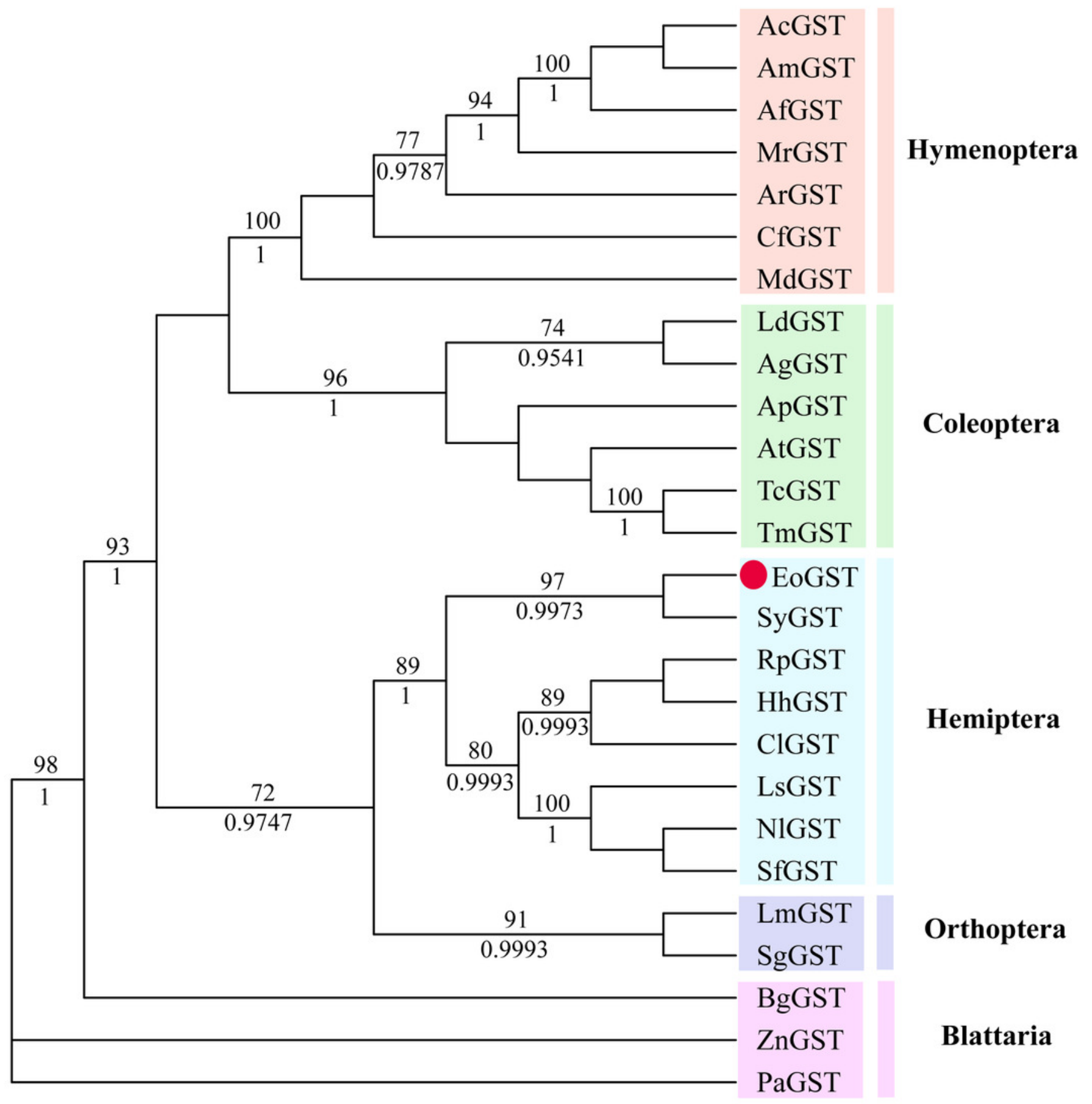




\section{Figure 10}

SDS-PAGE analysis of expression (A) and Western Blot analysis of fusion protein purification (B).

A, M1: Protein molecular weight marker; 1: Expressed product of recombinant EoGSRs1 protein without induction with IPTG at $11{ }^{\circ} \mathrm{C} ; 2$ : Expressed product of recombinant EoGSRs1 protein with induction with IPTG at $11^{\circ} \mathrm{C}$; 3 : The supernatant of recombinant EoGSRs1 protein with induction with IPTG at $11{ }^{\circ} \mathrm{C}$; 4: The precipitant of recombinant EoGSRs1 protein with induction with IPTG at $11{ }^{\circ} \mathrm{C}$. B, M2: Protein molecular weight marker; 1: Purified sample. 
A

$\mathrm{kD}$

M1 $12123 \quad 4$

B

kD $\mathrm{M} 2 \quad 1$

116.0
66.2

100

70

45.0

55

40

35.0

30

25.0

25

18.4

14.4

14 
Figure 11

Enzymatic kinetics of the purified recombinant EoGSRs1 protein $(A)$ and influence of temperature $(B)$ and $\mathrm{pH}(\mathrm{C})$ on the enzyme activity of the purified recombinant EoGSRs1 protein.

Data in the figure are mean $\pm \mathrm{SE}$. 

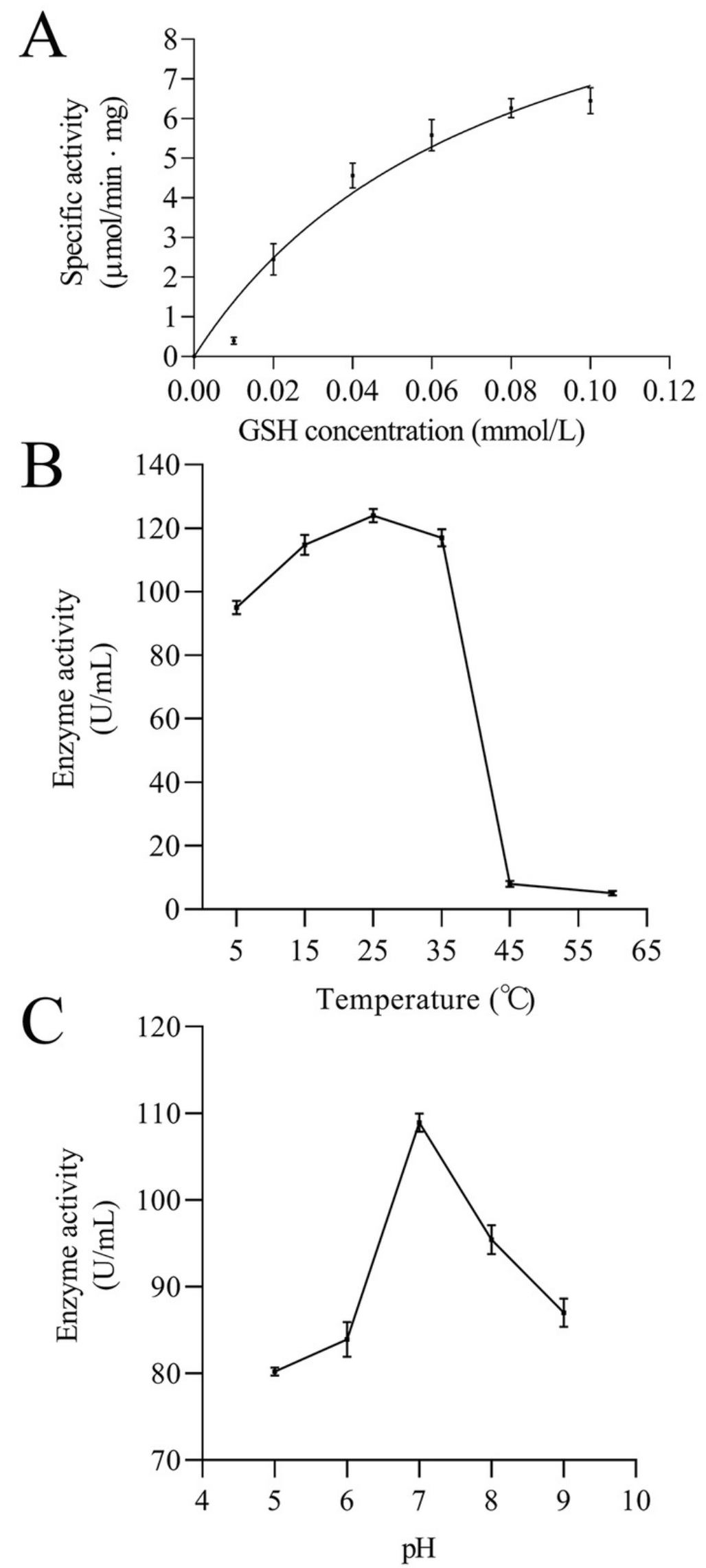